\title{
BMJ Open Incidence and duration of type-specific human papillomavirus infection in high-risk HPV-naïve women: results from the control arm of a phase II HPV-16/18 vaccine trial
}

To cite: Ramanakumar AV, Naud P, Roteli-Martins CM, et al. Incidence and duration of type-specific human papillomavirus infection in high-risk HPV-naïve women: results from the control arm of a phase II HPV-16/18 vaccine trial. BMJ Open 2016;6:e011371 doi:10.1136/bmjopen-2016011371

- Prepublication history and additional material is available. To view please visit the journal (http://dx.doi.org/ 10.1136/bmjopen-2016011371).

Part of this analysis has been presented previously: Ramanakumar AV, Naud P, Roteli-Martins CM, de Carvalho NS, de Borba PC, Teixeira JC, Blatter M, Schuind $A$, Dubin $G$ and Franco EL, for the HPV-007 Study Group. HPV infection incidence and duration in previously unexposed women. 27th International Papillomavirus Conference and Clinical Workshop, 2011, Berlin, Germany

Received 1 February 2016 Revised 26 April 2016 Accepted 15 June 2016 CrossMark

For numbered affiliations see end of article.

Correspondence to eduardo.franco@mcgill.ca

Agnihotram V Ramanakumar, ${ }^{1}$ Paulo Naud, ${ }^{2}$ Cecilia M Roteli-Martins, ${ }^{3}$ Newton S de Carvalho, ${ }^{4}$ Paola C de Borba, ${ }^{5}$ Julio C Teixeira, ${ }^{6}$ Mark Blatter, ${ }^{7}$ Anna-Barbara Moscicki, ${ }^{8}$ Diane M Harper, ${ }^{9}$ Barbara Romanowski, ${ }^{10}$ Stephen K Tyring, ${ }^{11}$ Brian Ramjattan, ${ }^{12}$ Anne Schuind, ${ }^{13}$ Gary Dubin, ${ }^{13}$ Eduardo L Franco, ${ }^{1}$ for the HPV-007 Study Group

\section{ABSTRACT}

Objectives: Persistence of human papillomaviruses (HPVs) is necessary for cervical carcinogenesis. We evaluated incidence and duration of type-specific HPV infections and the influence of age and number of sexual partners.

Methods: Data were obtained from 553 women (15-25 years), who were seronegative and DNA-negative for high-risk HPV (HR-HPV) types and were enrolled in the placebo arm of a randomised trial of the HPV-16/18 vaccine (NCT00689741/

NCT00120848). They were followed for 6.3 years. Cervicovaginal samples were self-collected at 3-month intervals for up to 27 months, and cervical samples were collected by clinicians at 6 -month intervals until study end. Samples were tested for HPV types using a broad-spectrum PCR assay. Incidence rate ratios (RRs) and $95 \%$ Cls were used to estimate the association among age, sexual habits and HPV acquisition.

Results: Incidence rates $(95 \% \mathrm{Cl})$ using cervical samples were 11.8 (10.4 to 13.4) and 5.6 (4.7 to 6.6) per 1000 women-months for HR-HPVs and low-risk HPVs (LR-HPVs), respectively. Equivalent rates in combined cervicovaginal and cervical samples were 17.2 (15.4 to 19.2) and 6.9 (5.9 to 8.0), respectively. 54 per cent of HR-HPV types from combined cervicovaginal and cervical samples persisted for 1 year compared with $32.3 \%$ for LR-HPV types. The risk of acquiring any HPV infection was higher among women aged $<21$ years ( $\mathrm{RR}=1.33,95 \% \mathrm{Cl} 1.1$ to 1.7 ) and women having $>1$ sexual partner $(\mathrm{RR}=1.83,95 \%$ $\mathrm{Cl} 1.4$ to 2.4) at baseline.

Conclusions: HR-HPV infections were more common and lasted longer on average than LR-HPV infections. HPV acquisition was more common in younger women with multiple sexual partners.

Trial registration number: NCT00689741, NCT00120848; Post-results.

\section{Strengths and limitations of this study}

- This study looks into the epidemiology of human papillomavirus (HPV) by assessing the impact and duration of specific HPV-type infections and by taking into account the age and the number of sexual partners.

- Improved understanding of type-specific HPV incidence and persistence may assist in designing cervical cancer screening algorithms based on molecular testing for high-risk HPVs.

- We analysed data from women aged 15-25 years who participated as control within a randomised clinical trial looking at the efficacy of the HPV-16/ 18 AS04-adjuvanted vaccine.

- The envisioned study limitation is the duration of self-collected samples over 2 years, which is counterbalanced by the duration of other samples collected by clinicians (over 6 years).

\section{INTRODUCTION}

Human papillomavirus (HPV) is the cause of cervical cancer. ${ }^{1}{ }^{2}$ HPV infection is usually asymptomatic and generally clears within 2 years for most infected individuals; yet a small proportion of infections persist and progress towards cervical cancer. ${ }^{3-7}$ The risk of cervical neoplasia is greatest among women with persistent high-risk HPV (HR-HPV) infections, which normally persist longer than those associated with low-risk HPV (LR-HPV) types. ${ }^{6-10}$ Understanding the natural history of HPV infection and its progression to cervical neoplasia is essential in planning successful cervical cancer control programmes. $^{11}{ }^{12}$ Determinants of HPV 
infection, transmission and development of cervical cancer include sexual habits, use of oral contraceptives, multiparity and smoking. ${ }^{13} 14$

Currently, little is known about the duration of infections with different HPV types. ${ }^{2} 351516$ Previous studies conducted on the natural history of HPV have mostly focused on broader groups of HPV types, have considered prevalence rather than incidence of infections or have been limited to cohort data with short follow-up. ${ }^{16-23}$

In the current study, we retrospectively analysed cohort data from participants enrolled in the placebo arm of a randomised controlled trial assessing the efficacy of the HPV-16/18 AS04-adjuvanted vaccine (Cervarix, GSK Vaccines) in young healthy women (NCT00689741). Clinician-collected cervical and self-collected cervicovaginal samples were obtained and used complementarily to study persistence and clearance of HPV infections. This trial recruited prescreened women not showing any serological or virological evidence of HR-HPV infections. This permitted assessing the type-specific incidence and duration of HPV infections among women presumably without prior exposure to infections with specific HR-HPVs.

\section{METHODS}

Study design and participants

A phase II, double-blind, randomised controlled trial of HPV-16/18 AS04-adjuvanted vaccine was conducted among 1113 young women aged 15-25 years. Detailed information on the design and follow-up procedures has been presented elsewhere. ${ }^{24}$ Briefly, following an initial phase of recruitment between July 2000 and September 2001, participants who were followed up until 18 months were asked to participate in an extended follow-up period until 27 months after receiving the first vaccine dose (HPV-001 (NCT00689741, Clinicaltrials.gov)). On completion of this phase, vaccine and placebo recipients were invited to participate in a long-term follow-up study of 3-year duration (up to 76 months) (HPV-007 (NCT00120848, Clinicaltrials.gov)). ${ }^{25}{ }^{26}$ Online supplementary figure 1 depicts the successive phases of the study.

The current analysis was restricted to a cohort of 553 individuals randomised to the placebo arm of this trial (received only aluminium hydroxide adjuvant). Women who were seronegative for HPV16 and HPV18 antibodies and HPV DNA-negative for 14 HR-HPV types $(16,18$, $31,33,35,39,45,51,52,56,58,59,66$ and 68) at screening visit had no more than six sexual partners and had no prior abnormal Pap smear or treatment for cervical disease were enrolled in this study. Women who participated in the initial phase and received three doses of placebo were eligible to participate in the extended and long-term follow-up phases. ${ }^{26}$

The study protocol and written informed consent, obtained at the screening visit from all participants or from a legally acceptable representative for those younger than the legal age of consent, were approved by independent ethics committees or institutional review boards of the respective study centres (see online supplementary table S1).

\section{Specimen collection and HPV DNA testing}

Cervical samples were collected for cytology and HPV DNA testing at the screening visit; at months 6,12 and 18 in the initial phase and every 6 months in the longterm follow-up period (after vaccination). Self-collected cervicovaginal samples were obtained at months 0,6 and then every 3 months until the end of the extended follow-up phase (see online supplementary figure 1). Colposcopy and histology were carried out according to a standardised protocol. ${ }^{24-26}$ DNA was isolated from the specimens and was tested for $25 \mathrm{HPV}$ genotypes $(6,11$, $16,18,31,33,34,35,39,40,42,43,44,45,51,52,53$, $54,56,58,59,66,68,70$ and 74) using the broadspectrum PCR SPF $10 \mathrm{LiPA}_{25}$ system $^{24}$ and by type-specific PCR for HPV types 16 and 18. HPV types 16, 18, 31, 33, $35,39,45,51,52,56,58,59,66$ and 68 were classified as HR-HPV types and the remainder as LR-HPV types. HPV types were also grouped according to Alphapapillomavirus species 6, 7, 8, 9 and 10 of the genus Alphapapillomavirus.

\section{Statistical analysis}

Analyses were performed for type-specific and/or grouped HPV infections (ie, LR-HPV, HR-HPV, any HPV or HPV $\alpha$ species). Combined clinician-collected cervical and self-collected cervicovaginal samples were used in all statistical analyses unless otherwise specified. We used several analytic approaches to study the natural history of cervical HPV infection.

The incidence rate for a given HPV genotype was calculated for women at risk for that type even if they were positive for other types. The cumulative probability of acquiring grouped HPV infection (eg, HR-HPV, LR-HPV or by $\alpha$ species) over the entire study period was estimated using the Kaplan-Meier (K-M) method. For clearance estimates, two different definitions were used. In the liberal (less stringent) definition, time to clearance for a given type was defined as the time elapsed between initial positivity and the visit when a participant was no longer positive for that type. In the conservative definition (stringent), we considered clearance to have occurred only after two consecutively negative visits had elapsed. The K-M method was also used to estimate the proportion of women who remained positive for grouped HPV infections by considering their first infection as the index infection since time 0 . In the case of multiple and coinfections within the HR groups or LR groups, their longest persisting infection must have been cleared in order to assign clearance status. Infections were only considered to be cleared when a women was no longer positive for any HR-HPV or LR-HPV types.

Incidence rate ratios (RRs) and 95\% CIs were computed to estimate the association among age $(<21,21+$ 
Table 1 Incidence of infections with individual and grouped HPV types according to the type of cell sampling

\begin{tabular}{|c|c|c|c|c|c|c|}
\hline \multirow[b]{2}{*}{$\begin{array}{l}\text { HPV type, } \\
\text { species }\end{array}$} & \multicolumn{3}{|c|}{ Combined cervical and cervicovaginal samples } & \multicolumn{3}{|c|}{ Cervical samples only } \\
\hline & $\begin{array}{l}\text { Women-months } \\
\text { of follow-up }\end{array}$ & $\begin{array}{l}\text { Incident } \\
\text { cases }\end{array}$ & $\begin{array}{l}\text { Incident rate per } \\
1000 \text { women-months } \\
(95 \% \mathrm{Cl})\end{array}$ & $\begin{array}{l}\text { Women-months } \\
\text { of follow-up }\end{array}$ & $\begin{array}{l}\text { Incident } \\
\text { cases }\end{array}$ & $\begin{array}{l}\text { Incident rate per } \\
1000 \text { women-months } \\
(95 \% \mathrm{Cl})\end{array}$ \\
\hline HPV6 & 27928 & 53 & 1.90 (1.45 to 2.48$)$ & 28033 & 40 & $1.43(1.05$ to 1.95$)$ \\
\hline HPV11 & 28971 & 26 & 0.90 (0.61 to 1.32$)$ & 29002 & 16 & $0.55(0.34$ to 0.90$)$ \\
\hline HPV16 & 25976 & 108 & 4.16 (3.44 to 5.02$)$ & 26723 & 84 & 3.14 (2.54 to 3.89$)$ \\
\hline HPV18 & 27264 & 72 & 2.64 (2.10 to 3.33$)$ & 27843 & 52 & 1.87 (1.42 to 2.45$)$ \\
\hline HPV31 & 27874 & 56 & 2.01 (1.55 to 2.61$)$ & 28140 & 41 & 1.46 (1.07 to 1.98$)$ \\
\hline HPV33 & 28600 & 31 & $1.08(0.76$ to 1.54$)$ & 28602 & 21 & $0.73(0.48$ to 1.13$)$ \\
\hline HPV34 & 29443 & 8 & $0.27(0.14$ to 0.54$)$ & 29231 & 4 & $0.14(0.05$ to 0.36$)$ \\
\hline HPV35 & 28992 & 23 & $0.79(0.53$ to 1.19$)$ & 28762 & 19 & $0.66(0.42$ to 1.04$)$ \\
\hline HPV39 & 27840 & 62 & 2.23 (1.74 to 2.86$)$ & 27933 & 48 & 1.72 (1.29 to 2.28$)$ \\
\hline HPV40 & 28909 & 25 & $0.86(0.58$ to 1.28$)$ & 29068 & 13 & 0.45 (0.26 to 0.77$)$ \\
\hline HPV42 & 29313 & 13 & $0.44(0.26$ to 0.76$)$ & 29210 & 6 & 0.21 (0.09 to 0.46$)$ \\
\hline HPV43 & 28989 & 21 & $0.72(0.47$ to 1.11$)$ & 29068 & 11 & $0.38(0.21$ to 0.68$)$ \\
\hline HPV44 & 29058 & 24 & $0.83(0.55$ to 1.23$)$ & 28864 & 19 & 0.66 (0.42 to 1.03$)$ \\
\hline HPV45 & 28867 & 33 & $1.14(0.81$ to 1.61$)$ & 28595 & 29 & $1.01(0.70$ to 1.46$)$ \\
\hline HPV51 & 26348 & 98 & 3.72 (3.05 to 4.53$)$ & 27339 & 72 & 2.63 (2.09 to 3.32$)$ \\
\hline HPV52 & 26233 & 91 & 3.47 (2.82 to 4.26$)$ & 27076 & 68 & 2.51 (1.98 to 3.19$)$ \\
\hline HPV53 & 26485 & 85 & 3.21 (2.59 to 3.97 ) & 26952 & 69 & 2.56 (2.02 to 3.24$)$ \\
\hline HPV54 & 28146 & 42 & 1.49 (1.10 to 2.02$)$ & 28447 & 31 & 1.09 (0.77 to 1.55$)$ \\
\hline HPV56 & 27879 & 58 & 2.08 (1.61 to 2.69$)$ & 28289 & 42 & 1.48 (1.10 to 2.01$)$ \\
\hline HPV58 & 28614 & 34 & $1.19(0.85$ to 1.66$)$ & 28591 & 26 & 0.91 (0.62 to 1.34$)$ \\
\hline HPV59 & 28809 & 26 & 0.90 (0.61 to 1.33$)$ & 28925 & 16 & 0.55 (0.34 to 0.90$)$ \\
\hline HPV66 & 27222 & 69 & 2.53 (2.00 to 3.21$)$ & 27579 & 54 & 1.96 (1.50 to 2.56$)$ \\
\hline HPV68 & 27832 & 53 & 1.90 (1.45 to 2.49$)$ & 28241 & 41 & 1.45 (1.07 to 1.97$)$ \\
\hline HPV70 & 29061 & 22 & $0.76(0.50$ to 1.15$)$ & 28970 & 17 & 0.59 (0.36 to 0.94$)$ \\
\hline HPV74 & 28657 & 34 & $1.19(0.85$ to 1.66$)$ & 28853 & 24 & 0.83 (0.56 to 1.24$)$ \\
\hline Any HPV & 15530 & 320 & 20.61 (18.47 to 22.99$)$ & 18859 & 265 & $14.05(12.46$ to 15.85$)$ \\
\hline HR-HPV & 17518 & 301 & $17.18(15.35$ to 19.24$)$ & 20806 & 246 & $11.82(10.43$ to 13.40$)$ \\
\hline LR-HPV & 23550 & 162 & $6.88(5.90$ to 8.02$)$ & 24686 & 137 & 5.55 (4.69 to 6.56$)$ \\
\hline Species-6 & 23277 & 164 & 7.05 (6.05 to 8.21$)$ & 24791 & 132 & $5.32(4.49$ to 6.31$)$ \\
\hline Species-7 & 23123 & 173 & 7.48 (6.45 to 8.68$)$ & 24906 & 138 & 5.54 (4.69 to 6.55$)$ \\
\hline Species-8 & 28300 & 40 & $1.41(1.04-1.93)$ & 28768 & 23 & $0.80(0.53$ to 1.20$)$ \\
\hline Species-9 & 21424 & 212 & 9.90 (8.65 to 11.32$)$ & 23718 & 163 & 6.87 (5.89 to 8.01$)$ \\
\hline Species-10 & 26661 & 91 & 3.41 (2.78 to 4.19$)$ & 27371 & 67 & 2.45 (1.93 to 3.11$)$ \\
\hline
\end{tabular}

years), number of sexual partners $(0 / 1,2+)$ and the risk of HPV acquisition. K-M graphs and log-rank tests, used to identify differences in HPV acquisition and clearance in women, were stratified by age and number of sexual partners.

\section{RESULTS}

At the time of this analysis, there were 6618 samples with HPV DNA typing, with an average of 9 visits per woman. The mean and median follow-up durations were 51.8 and 68.2 months, respectively. Online supplementary figure 2 shows for each study visit, the distribution of the actual time elapsed since screening, with the majority of participants returning on time for scheduled follow-up visits. Approximately $60 \%$ of participants returned for the follow-up beyond 6 years (see online supplementary figure 2). Online supplementary table S2 shows the sociodemographic characteristics and smoking and reproductive health history for the 553 women included in the cohort. Slightly more than half of the sample was enrolled in American and Canadian centres and the remainder in multiple centres in Brazil. Most women were single or divorced and attained more than high school education. More than $70 \%$ of the women had at most one lifetime sexual partner.

\section{Incidence of HPV infection}

During follow-up, any HPV infection was detected in $320 / 553(57.9 \%)$ initially enrolled women; 201/553 $(36.3 \%)$ were infected with multiple types at the same visit, regardless of the sampling method. 
Table 2 Median and mean durations of infection in months and proportion of persistent infection for individual and grouped HPV types (combined cervical and cervicovaginal samples)

Liberal definition: clearance defined as first negative results postinfection

\begin{tabular}{|c|c|c|c|c|c|c|c|c|}
\hline $\begin{array}{l}\text { HPV type, } \\
\text { species }\end{array}$ & $\begin{array}{l}\text { No. of } \\
\text { events }\end{array}$ & $\begin{array}{l}\text { Median duration of } \\
\text { infection }(95 \% \mathrm{CI})\end{array}$ & $\begin{array}{l}\text { Mean duration of } \\
\text { infection }(95 \% \mathrm{Cl})\end{array}$ & $\begin{array}{l}\% \text { of persistent } \\
\text { infection } \\
\text { (1-year) }\end{array}$ & $\begin{array}{l}\text { No. of } \\
\text { events }\end{array}$ & $\begin{array}{l}\text { Median duration of } \\
\text { infection }(95 \% \mathrm{Cl})\end{array}$ & $\begin{array}{l}\text { Mean duration of } \\
\text { infection }(95 \% \mathrm{Cl})\end{array}$ & $\begin{array}{l}\% \text { of persistent } \\
\text { infection } \\
\text { (1-year) }\end{array}$ \\
\hline HPV6 & 43 & 6.5 (5.7 to 9.0$)$ & 9.5 (7.5 to 11.5$)$ & 16.1 & 41 & 7.2 (5.7 to 9.6$)$ & 10.0 (7.9 to 12.2$)$ & 18.2 \\
\hline HPV11 & 24 & $7.2(5.8$ to 11.7$)$ & $9.2(6.9$ to 11.4$)$ & 25.5 & 23 & $9.8(6.0$ to 12.6$)$ & $11.0(7.9$ to 14.1$)$ & 32.3 \\
\hline HPV16 & 82 & 11.8 (10.3 to 16.7$)$ & 15.8 (13.0 to 18.5$)$ & 49.0 & 69 & 16.9 (11.7 to 22.6$)$ & 21.3 (17.3 to 25.2 ) & 60.6 \\
\hline HPV18 & 61 & $6.2(5.8$ to 11.1$)$ & 10.8 (8.3 to 13.3$)$ & 33.0 & 57 & 7.7 (5.9 to 12.2$)$ & 12.1 (9.4 to 14.9$)$ & 39.3 \\
\hline HPV31 & 44 & 7.4 (5.9 to 12.1$)$ & $10.9(8.4$ to 13.4$)$ & 36.6 & 39 & $10.6(6.7$ to 16.7$)$ & $14.0(10.8$ to 17.1$)$ & 46.7 \\
\hline HPV33 & 27 & $8.0(6.2$ to 10.6$)$ & $10.0(7.3$ to 12.7$)$ & 27.1 & 24 & $8.7(6.2$ to 13.3$)$ & 11.3 (8.3 to 14.3$)$ & 40.2 \\
\hline HPV34 & 8 & $6.0(2.5$ to 11.5$)$ & 8.0 (5.1 to 10.8$)$ & 12.5 & 8 & 6.0 (2.5 to 11.5$)$ & $8.0(5.1$ to 10.8$)$ & 12.5 \\
\hline HPV35 & 21 & $12.1(6.2$ to 16.6$)$ & $14.8(10.7$ to 18.8$)$ & 50.3 & 16 & 14.3 (11.3 to 24.6$)$ & 17.6 (12.7 to 22.5$)$ & 59.0 \\
\hline HPV39 & 49 & 6.5 (6.0 to 8.3$)$ & $11.0(8.5$ to 13.5$)$ & 30.2 & 44 & $8.1(6.5$ to 14.1$)$ & 13.8 (10.7 to 16.9$)$ & 40.4 \\
\hline HPV40 & 23 & $6.0(4.4$ to 8.1$)$ & $7.2(5.5$ to 8.9$)$ & 13.5 & 21 & $6.0(4.4$ to 9.5$)$ & 7.7 (5.8 to 9.7$)$ & 17.4 \\
\hline HPV42 & 11 & 6.0 (3.2 to 10.0$)$ & 6.8 (5.2 to 8.3$)$ & 0.0 & 9 & 7.2 (3.2 to 34.8$)$ & 13.0 (5.2 to 20.8$)$ & 22.9 \\
\hline HPV43 & 20 & $5.9(4.4$ to 8.5$)$ & $7.9(5.5$ to 10.4$)$ & 17.1 & 15 & $6.0(4.4$ to 16.6$)$ & $10.0(6.8$ to 13.2$)$ & 31.0 \\
\hline HPV44 & 21 & 6.9 (4.4 to 13.9$)$ & $11.2(7.0$ to 15.4$)$ & 32.6 & 18 & 7.0 (6.0 to 19.3$)$ & 14.4 (9.1 to 19.8$)$ & 39.4 \\
\hline HPV45 & 28 & 7.0 (5.5 to 9.2$)$ & $8.9(6.8$ to 11.0$)$ & 21.8 & 25 & $7.2(5.6$ to 11.6$)$ & 9.8 (7.3 to 12.2$)$ & 24.9 \\
\hline HPV51 & 82 & $7.4(6.0$ to 10.6$)$ & 11.3 (9.1 to 13.5$)$ & 33.6 & 69 & $10.3(6.9$ to 12.5$)$ & 15.4 (11.7 to 19.1$)$ & 40.8 \\
\hline HPV52 & 76 & $10.7(7.2$ to 14.5$)$ & 14.9 (12.3 to 17.5$)$ & 45.3 & 64 & 16.8 (10.8 to 21.4$)$ & 19.9 (16.2 to 23.6$)$ & 60.3 \\
\hline HPV53 & 81 & $11.2(9.3$ to 12.0$)$ & $12.0(10.3$ to 13.6$)$ & 40.8 & 70 & 12.1 (11.1 to 14.7$)$ & 15.5 (12.9 to 18.0$)$ & 50.1 \\
\hline HPV54 & 38 & $6.0(5.3$ to 7.6$)$ & $8.6(6.8$ to 10.4$)$ & 29.5 & 32 & 6.9 (5.8 to 12.5$)$ & $10.2(8.0$ to 12.4$)$ & 39.4 \\
\hline HPV56 & 46 & 6.1 (5.3 to 12.1$)$ & 11.9 (8.8 to 15.0$)$ & 36.5 & 39 & $12.1(6.0$ to 18.3$)$ & $14.7(11.0$ to 18.5$)$ & 52.9 \\
\hline HPV58 & 26 & 9.7 (5.3 to 12.0$)$ & 11.5 (8.4 to 14.6$)$ & 30.8 & 24 & 11.4 (7.5 to 21.8$)$ & $13.7(10.4$ to 17.0$)$ & 44.8 \\
\hline HPV59 & 25 & 7.0 (5.3 to 11.6$)$ & $8.5(6.5$ to 10.5$)$ & 28.1 & 22 & 7.3 (5.3 to 13.4$)$ & 9.0 (6.8 to 11.2$)$ & 34.4 \\
\hline HPV66 & 59 & 6.5 (5.8 to 9.3 ) & 9.4 (7.7 to 11.0$)$ & 25.4 & 50 & 9.0 (6.0 to 11.6$)$ & 12.4 (9.6 to 15.2$)$ & 36.7 \\
\hline HPV68 & 45 & 6.2 (5.8 to 12.3$)$ & $10.7(8.4$ to 13.1$)$ & 36.6 & 42 & $7.8(6.0$ to 14.0$)$ & $12.7(10.1$ to 15.3$)$ & 45.1 \\
\hline HPV70 & 18 & 10.2 (5.5 to 18.9$)$ & 18.0 (9.9 to 26.0$)$ & 42.5 & 14 & 12.5 (6.0 to 25.8$)$ & 22.5 (12.8 to 32.2$)$ & 53.1 \\
\hline HPV74 & 24 & 6.5 (5.3 to 18.7$)$ & 12.2 (8.8 to 15.6$)$ & 42.0 & 22 & $11.0(5.3$ to 18.7$)$ & 14.1 (9.9 to 18.3$)$ & 48.6 \\
\hline Any HPV & 251 & 14.5 (11.8 to 16.8$)$ & 21.9 (19.4 to 24.3$)$ & 53.7 & 210 & 25.0 (18.0 to 27.9$)$ & 29.7 (26.7 to 32.7 ) & 66.4 \\
\hline HR-HPV & 232 & 13.7 (10.6 to 16.8$)$ & 19.5 (17.3 to 21.8$)$ & 54.1 & 187 & 24.6 (20.1 to 28.8$)$ & 28.1 (25.0 to 31.2 ) & 67.4 \\
\hline LR-HPV & 150 & 8.6 (6.5 to 10.9$)$ & $11.6(10.1$ to 13.1$)$ & 32.3 & 130 & $11.6(10.2$ to 12.5$)$ & 14.8 (12.8 to 16.8$)$ & 44.3 \\
\hline Species-6 & 146 & 9.9 (7.5 to 11.6$)$ & 12.1 (10.6 to 13.7$)$ & 39.3 & 122 & 11.7 (9.7 to 13.0$)$ & 16.5 (14.0 to 19.0$)$ & 48.9 \\
\hline Species-7 & 148 & 7.3 (6.2 to 11.3$)$ & $12.6(10.7$ to 14.4$)$ & 38.9 & 133 & $11.7(7.3$ to 14.1$)$ & 16.4 (14.0 to 18.7$)$ & 49.4 \\
\hline Species-8 & 40 & $5.9(5.0$ to 6.2$)$ & $7.4(5.8$ to 9.0$)$ & 15.0 & 32 & $6.0(5.5$. to 9.5$)$ & $8.8(6.7$ to 11.0$)$ & 24.1 \\
\hline Species-9 & 167 & 13.1 (10.6 to 16.7$)$ & $16.7(14.7$ to 18.8$)$ & 52.1 & 136 & 20.0 (15.9 to 23.3 ) & 23.9 (20.7 to 27.1$)$ & 65.1 \\
\hline Species-10 & 79 & $7.0(6.0$ to 8.8$)$ & 10.0 (8.3 to 11.7$)$ & 29.0 & 72 & $8.7(6.2$ to 11.7$)$ & $11.9(9.8$ to 14.0$)$ & 35.8 \\
\hline
\end{tabular}

Conservative definition: clearance defined as two consecutive negative results postinfection

$\alpha$ species 6=HPVs 53, 56, 66; $\alpha$ species 7=HPVs 18, 39, 45, 59, 68, 70; $\alpha$ species 8=HPVs 40, 43; $\alpha$ species 9=HPVs 16, 31, 33, 35, 52, 58; $\alpha$ species $10=H P V s$, 11,44

HPV, human papillomavirus; HR-HPV, high-risk HPV $(16,18,31,33,35,39,45,51,52,56,58,59,66$ and 68); LR-HPV, low-risk HPV (6, 11, 34, 40, 42, 43, 44, 53, 54, 59, 70 and 74). 
Table 3 Incidence rate of infection with individual and grouped HPV types using combined cervical and cervicovaginal samples, according to age and number of sexual partners

\begin{tabular}{|c|c|c|c|c|c|c|}
\hline \multirow[b]{2}{*}{ HPV type } & \multicolumn{3}{|l|}{ Age } & \multicolumn{3}{|l|}{ Number of sexual partners } \\
\hline & $\begin{array}{l}21+\text { years } \\
\text { IR per } 1000 \\
\text { women-months }(95 \% \mathrm{Cl})\end{array}$ & $\begin{array}{l}<21 \text { years } \\
\text { IR per } 1000 \\
\text { women-months }(95 \% \mathrm{Cl})\end{array}$ & RR (95\% Cl) & $\begin{array}{l}0 / 1 \\
\text { IR per } 1000 \\
\text { women-months }(95 \% \mathrm{CI})\end{array}$ & $\begin{array}{l}2+ \\
\text { IR per } 1000 \\
\text { women-months }(95 \% \mathrm{CI})\end{array}$ & RR (95\% Cl) \\
\hline HPV6 & 1.14 (0.69 to 1.89$)$ & 2.59 (1.89 to 3.56$)$ & 2.26 (1.22 to 4.44$)$ & $1.47(0.90$ to 2.41$)$ & $2.16(1.48$ to 3.15$)$ & $1.46(0.76$ to 2.91$)$ \\
\hline HPV11 & $0.60(0.30$ to 1.2$)$ & $1.16(0.73$ to 1.84$)$ & $1.93(0.80$ to 5.14$)$ & $0.53(0.24$ to 1.19$)$ & 0.99 (0.58 to 1.71$)$ & 1.86 (0.66 to 5.97$)$ \\
\hline HPV16 & 2.49 (1.75 to 3.55$)$ & 5.64 (4.51 to 7.07$)$ & 2.26 (1.47 to 3.56$)$ & 3.22 (2.29 to 4.54$)$ & 4.98 (3.84 to 6.45$)$ & 1.54 (0.99 to 2.45$)$ \\
\hline HPV18 & $2.05(1.40$ to 3.01$)$ & 3.18 (2.38 to 4.25$)$ & 1.55 (0.94 to 2.62$)$ & 1.57 (0.97 to 2.52$)$ & 3.30 (2.42 to 4.50$)$ & 2.11 (1.17 to 3.96$)$ \\
\hline HPV31 & 1.47 (0.94 to 2.30$)$ & 2.50 (1.81 to 3.45$)$ & 1.71 (0.96 to 3.14$)$ & $0.80(0.42$ to 1.55$)$ & 2.78 (1.99 to 3.89$)$ & 3.46 (1.62 to 8.20$)$ \\
\hline HPV33 & $0.91(0.52$ to 1.60$)$ & $1.17(0.74$ to 1.86$)$ & $1.29(0.59$ to 2.93$)$ & 0.81 (0.42 to 1.56$)$ & $1.57(1.01$ to 2.44$)$ & 1.93 (0.84 to 4.82$)$ \\
\hline HPV34 & 0.15 (0.04 to 0.59$)$ & $0.38(0.17$ to 0.85$)$ & 2.57 (0.46 to 26.0$)$ & 0.27 (0.09 to 0.82$)$ & $0.30(0.11$ to 0.80$)$ & $1.13(0.19$ to 7.71$)$ \\
\hline HPV35 & $0.75(0.41$ to 1.40$)$ & $0.83(0.48$ to 1.44$)$ & 1.11 (0.45 to 2.82$)$ & $0.72(0.36$ to 1.44$)$ & $0.84(0.46$ to 1.51$)$ & $1.16(0.42$ to 3.32$)$ \\
\hline HPV39 & 1.94 (1.31 to 2.88$)$ & 2.49 (1.81 to 3.44$)$ & 1.28 (0.75 to 2.22$)$ & 2.26 (1.51 to 3.37 ) & 2.40 (1.68 to 3.44$)$ & 1.06 (0.60 to 1.90$)$ \\
\hline HPV40 & 0.83 (0.46 to 1.49$)$ & 0.91 (0.54 to 1.53$)$ & 1.10 (0.46 to 2.67$)$ & 0.91 (0.49 to 1.68$)$ & $1.00(0.58$ to 1.71$)$ & 1.10 (0.45 to 2.80$)$ \\
\hline HPV42 & 0.45 (0.20 to 1.00$)$ & 0.44 (0.21 to 0.93$)$ & 0.98 (0.28 to 3.53$)$ & 0.09 (0.01 to 0.63$)$ & 0.84 (0.46 to 1.51$)$ & 9.48 ( 1.38 to 408.0$)$ \\
\hline HPV43 & $0.45(0.20$ to 1.00$)$ & 0.97 (0.58 to 1.61$)$ & 2.17 (0.79 to 6.81$)$ & 0.91 (0.49 to 1.68$)$ & $0.60(0.30$ to 1.21$)$ & 0.67 (0.23 to 1.88$)$ \\
\hline HPV44 & $0.38(0.16$ to 0.90$)$ & $1.21(0.77$ to 1.90$)$ & $3.23(1.17$ to 11.06$)$ & 0.71 (0.36 to 1.43$)$ & 0.68 (0.36 to 1.32$)$ & 0.96 (0.37 to 2.85$)$ \\
\hline HPV45 & $0.83(0.46$ to 1.50$)$ & $1.42(0.94$ to 2.16$)$ & $1.71(0.80$ to 3.91$)$ & 0.99 (0.55 to 1.79$)$ & 1.46 (0.93 to 2.29$)$ & 1.48 (0.67 to 3.44$)$ \\
\hline HPV51 & 2.66 (1.89 to 3.74$)$ & 4.53 (3.54 to 5.80$)$ & 1.71 (1.10 to 2.68$)$ & 3.09 (2.18 to 4.36$)$ & 4.59 (3.50 to 6.00$)$ & 1.49 (0.94 to 2.38$)$ \\
\hline HPV52 & $2.22(1.53$ to 3.21$)$ & 4.58 (3.57 to 5.87 ) & 2.07 (1.30 to 3.35$)$ & $2.90(2.03$ to 4.15$)$ & 3.85 (2.87 to 5.15$)$ & $1.33(0.82$ to 2.18$)$ \\
\hline HPV53 & 2.52 (1.78 to 3.59$)$ & 3.84 (2.94 to 5.01$)$ & 1.52 (0.96 to 2.44$)$ & 2.59 (1.78 to 3.78$)$ & 3.71 (2.75 to 5.00$)$ & $1.43(0.86$ to 2.41$)$ \\
\hline HPV54 & 0.91 (0.52 to 1.61$)$ & 1.94 (1.35 to 2.80$)$ & 2.13 (1.05 to 4.59$)$ & 1.38 (0.83 to 2.29$)$ & 1.67 (1.09 to 2.56$)$ & 1.21 (0.60 to 2.53$)$ \\
\hline HPV56 & 1.47 (0.93 to 2.30$)$ & 2.57 (1.87 to 3.53$)$ & 1.75 (0.99 to 3.22$)$ & 1.75 (1.11 to 2.74$)$ & 1.82 (1.21 to 2.75$)$ & 1.05 (0.54 to 2.03$)$ \\
\hline HPV58 & 0.98 (0.57 to 1.69$)$ & $1.38(0.90$ to 2.11$)$ & 1.40 (0.67 to 3.05$)$ & 0.91 (0.49 to 1.68$)$ & 1.23 (0.75 to 2.00$)$ & 1.35 (0.58 to 3.33$)$ \\
\hline HPV59 & $0.76(0.41$ to 1.40$)$ & 1.04 (0.63 to 1.69$)$ & 1.37 (0.59 to 3.38$)$ & $0.35(0.13$ to 0.94$)$ & 1.25 (0.76 to 2.04$)$ & 3.53 (1.14 to 14.52$)$ \\
\hline HPV66 & 1.48 (0.95 to 2.32$)$ & 3.43 (2.59 to 4.53$)$ & 2.31 (1.34 to 4.16$)$ & 2.70 (1.86 to 3.91$)$ & 2.62 (1.85 to 3.70$)$ & 0.97 (0.57 to 1.67$)$ \\
\hline HPV68 & 1.65 (1.07 to 2.53$)$ & 2.14 (1.51 to 3.02$)$ & 1.30 (0.73 to 2.37$)$ & 1.46 (0.90 to 2.39$)$ & 2.53 (1.78 to 3.60$)$ & 1.73 (0.92 to 3.39$)$ \\
\hline HPV70 & 0.68 (0.36 to 1.31$)$ & 0.83 (0.48 to 1.42$)$ & 1.21 (0.48 to 3.20$)$ & 0.62 (0.30 to 1.30$)$ & 0.84 (0.47 to 1.52$)$ & 1.35 (0.48 to 4.12$)$ \\
\hline HPV74 & 0.90 (0.51 to 1.58$)$ & 1.45 (0.95 to 2.20$)$ & 1.61 (0.76 to 3.58$)$ & 1.07 (0.61 to 1.89$)$ & 1.40 (0.88 to 2.22$)$ & 1.30 (0.59 to 2.97$)$ \\
\hline Any HPV & 17.58 (14.88 to 20.78$)$ & 23.48 (20.29 to 27.18$)$ & 1.33 (1.06 to 1.68$)$ & $15.63(12.90$ to 18.95$)$ & 28.66 (24.62 to 33.35$)$ & 1.83 (1.43 to 2.36$)$ \\
\hline HR-HPV & $13.80(11.58$ to 16.45$)$ & 20.60 (17.76 to 23.90$)$ & 1.49 (1.18 to 1.89$)$ & 13.34 (10.93 to 16.27$)$ & 22.88 (19.60 to 26.72$)$ & 1.72 (1.33 to 2.23$)$ \\
\hline LR-HPV & 5.94 (4.66 to 7.57$)$ & 7.78 (6.37 to 9.49$)$ & 1.31 (0.95 to 1.82$)$ & 6.37 (4.94 to 8.23$)$ & 7.46 (5.96 to 9.34$)$ & 1.17 (0.82 to 1.67$)$ \\
\hline Species-6 & 5.09 (3.93 to 6.60$)$ & $8.76(7.23$ to 10.60$)$ & $1.72(1.23$ to 2.42$)$ & 5.79 (4.44 to 7.56$)$ & 8.27 (6.66 to 10.27$)$ & $1.43(1.00$ to 2.05$)$ \\
\hline Species-7 & 6.88 (5.49 to 8.63$)$ & 8.10 (6.65 to 9.88$)$ & $1.18(0.86$ to 1.61$)$ & 5.10 (3.86 to 6.75$)$ & $9.92(8.13$ to 12.12$)$ & 1.94 (1.37 to 2.80$)$ \\
\hline Species-8 & $1.06(0.63$ to 1.79$)$ & $1.73(1.18$ to 1.73$)$ & $1.63(0.82$ to 3.38$)$ & 1.68 (1.06 to 2.66$)$ & $1.32(0.82$ to 2.11$)$ & $0.78(0.38$ to 1.61$)$ \\
\hline Species-9 & 7.23 (5.79 to 9.03 ) & $12.42(10.47$ to 14.73$)$ & 1.72 (1.29 to 2.30$)$ & 7.44 (5.84 to 9.49$)$ & $12.23(10.15$ to 14.73$)$ & 1.64 (1.20 to 2.27$)$ \\
\hline Species-10 & 1.98 (1.34 to 2.93$)$ & 4.75 (3.73 to 6.04$)$ & 2.40 (1.49 to 3.97$)$ & 2.47 (1.68 to 3.63$)$ & 3.81 (2.84 to 5.10$)$ & $1.54(0.93$ to 2.60$)$ \\
\hline
\end{tabular}



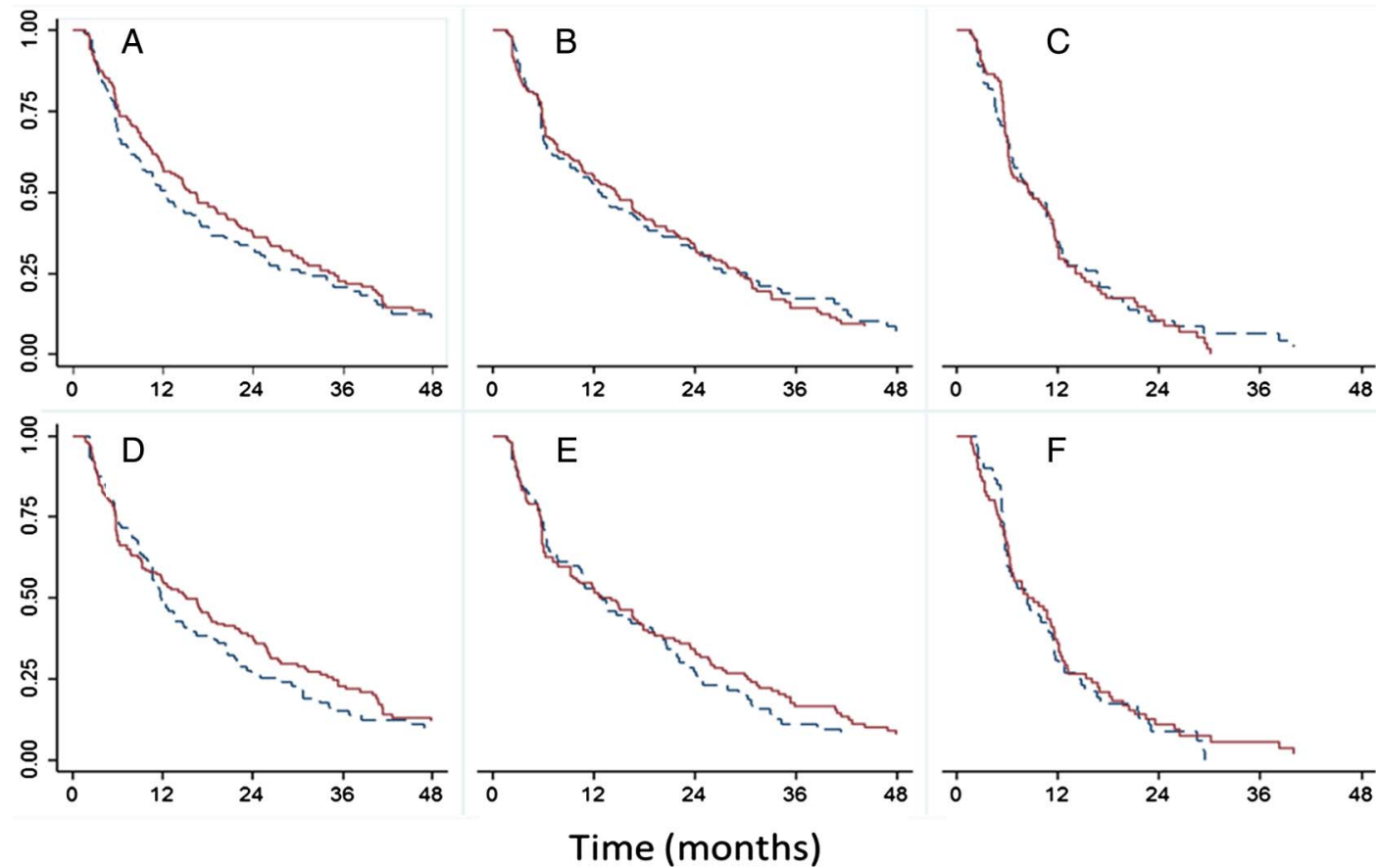

Figure 1 Cumulative probability of persistent detection of the first episode of HPV infection (as per liberal definition) over time stratified by age (upper graphs A, B, C; solid line $<21$ years and dashed line $\geq 21$ years) and sexual partners (lower graphs $D, E, F$; solid line $\geq 2$ partners, dashed line $0 / 1$ partner). Log-rank test $p$ values; $A=0.0806, B=0.1276, C=0.9338$, $\mathrm{D}=0.3436, E=0.4601, \mathrm{~F}=0.2186$. ( $\mathrm{A}$ and $\mathrm{D})$ Any HPV type; $(\mathrm{B}, \mathrm{E}) \mathrm{HR}$-HPV; and (C and F) LR-HPV. The Y-axis represents the probability that HPV infections remain detectable. Clearance of an infection episode as per the liberal definition (see text for details); combined cervical and cervicovaginal samples. HPV, human papillomavirus; HR-HPV, high-risk HPV; LR-HPV, low-risk HPV.

Table 1 shows the incidence rates of type-specific and grouped HPV infections in combined cervical and selfcollected cervicovaginal samples as well as in cervical samples. Kappa statistics showed an $85 \%$ agreement between self-collected and clinician-collected samples (results not shown). On the basis of analyses of the combined cervical and cervicovaginal samples, the five most common HPV types (incidence rate per 1000 womenmonths; 95\% CI) were HPV16 (4.2; 3.4 to 5.0), HPV51 (3.7; 3.1 to 4.5 ), HPV52 (3.5; 2.8 to 4.3), HPV53 (3.2; 2.6 to 4.0 ) and HPV18 (2.6; 2.1 to 3.3) (table 1). Using cervical samples only, the incidence rates were slightly lower and the most common types were similar with exception of HPV18 (table 1). The incidence rates $(95 \%$ CI) for any HR-HPV type and any LR-HPV type using combined cervical and cervicovaginal samples were 17.2 (15.4 to 19.2) and 6.9 (5.9 to 8.0), respectively. The corresponding values in cervical samples were 11.8 (10.4 to 13.4) and 5.6 (4.7 to 6.6), respectively (table 1 ). The cumulative rates of any HPV infection were $28.7 \%$ (1-year) and $49.7 \%$ (2 years) using either sampling technique (data not shown).

\section{Clearance of HPV infection}

The pattern of HPV clearance based on the two different definitions is shown in table 2. Using the liberal definition for combined cervical and cervicovaginal samples, more than half of the HR-HPVs $(54.1 \%)$ and nearly one-third of LR-HPVs $(32.3 \%)$ persisted for longer than 1 year. The median time (months; 95\% CI) to clear an infection tended to be longer for most HR-HPV types, for example, HPV16 (11.8; 10.3 to 16.7), HPV35 (12.1; 6.2 to 16.6$)$, HPV52 (10.7; 7.2 to 14.5$)$ compared to LR-HPV types, for example, HPV6 $(6.5 ; 5.7$ to 9.0$)$, HPV11 (7.2; 5.8 to 11.7$)$. The mean duration of infections was longer than the median durations and was between 7 and 22 months depending on the risk-based grouping (HR-HPV or LR-HPV). Further, when analyses were restricted to long-term follow-up (40-76 months), the median durations were 10.5 and 5.6 months for HR-HPV and LR-HPV types, respectively. On the other hand, when restricted to the 0-18 months' follow-up period and cervical samples, the corresponding median durations were 13.1 and 11.7 months, respectively.

As expected, the stringent definition of clearance yielded longer estimates of mean and median durations than the liberal definition, that is, 29.7 (95\% CI 26.7 to 32.7) and 25.0 (95\% CI 18.0 to 27.9) months versus 21.9 (19.4 to 24.3) and 14.5 (11.8 to 16.8) months, respectively, for estimates associated with any HPV type (table 2).

Further, in our cohort, $30 \%$ of LR-HPV and $49 \%$ of HR-HPV samples were accompanied by other HPV types at the same visit. Using liberal definition, women with multiple infections generally took a longer time to 

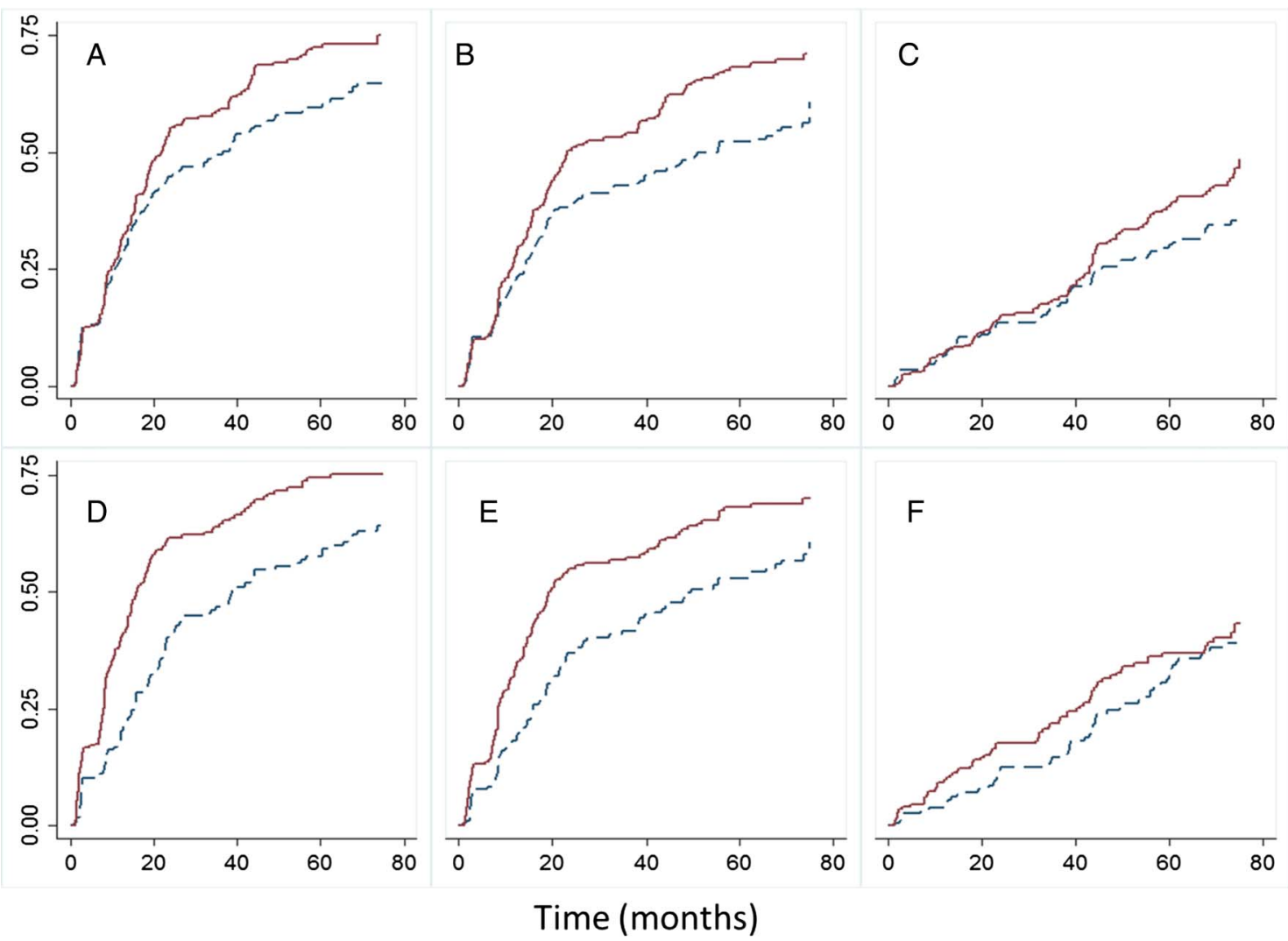

Figure 2 Cumulative probability of detecting an HPV infection over time stratified by the age group (upper graphs A, B, C; solid line $<21$ years and dashed line $\geq 21$ years) and number of sexual partners (lower graphs $D, E, F$; solid line $\geq 2$ partners and dashed line 0/1 partner). Log-rank test $p$ values; $A=0.0099, B<0.0001, C=0.122, D<0.0001, E=0.0007, F=0.2712$. (A and $D$ ) $A$ ny HPV type; (B and E), HR-HPV; and (C and F) LR-HPV. The Y-axis represents cumulative proportion of infections detected. Combined cervical and cervicovaginal samples. HPV, human papillomavirus; HR-HPV, high-risk HPV; LR-HPV, low-risk HPV.

clear their infections (median=20.6 months) compared to those with a single infection of any type (median=10.5 months).

\section{Age and number of sexual partners as risk factors}

Table 3 presents incidence RR according to age and number of sexual partners. Higher type-specific and grouped incidence (RRs $>1)$ was the rule among younger women $(<21$ years $)$ and among women with multiple sexual partners $(\geq 2$ partners). The risk of acquiring any type of HPV infection was 1.33 times (95\% CI 1.1 to 1.7 ) higher in women aged $<21$ years compared with women aged $\geq 21$ years. Likewise, women with more than one sexual partner were at 1.83 times (95\% CI 1.4 to 2.4) higher risk than those with no/single partner. While younger women $(<21$ years) had an increased risk of infection with HPV $\alpha$ species 6,9 and 10, those with multiple sexual partners had marginally increased risks of infection with HPV $\alpha$ species groups 7, 9 and 10.

The cumulative probability of clearance of HPV infections, according to the liberal definition and stratified by age and multiple sexual partners, is shown in figure 1. Younger women and women with multiple sexual partners took slightly longer to clear the infections, but differences were not significant based on log-rank tests.
Furthermore, the cumulative probability of detecting an HPV infection was significantly higher in younger women and women with multiple sexual partners, as depicted in figure 2.

\section{DISCUSSION}

We studied the early natural history of true incident genital HPV infections in a cohort characterised by serology and cervical sampling, in addition to a restriction in maximum number of sexual partners, which permitted ascertaining that participants had minimal previous exposure to HPV. Our results showed HR-HPV infections to be more common and of longer duration than LR-HPV infections. The study also revealed that younger women with multiple sex partners were at a higher risk of acquiring HPV infections than those with no/single sex partner.

Incidence rates of type-specific HPV infections were compared according to different sampling strategies: (1) clinician-collected cervical and (2) clinician plus selfcollected cervicovaginal sampling. The agreement between self-collected and clinician-collected samples for the detection of HPV DNA was reasonably good in this study population, that is, $85 \%$ of positive tests were observed when both samples were available, that is, 6,12 and 18 months. The incidence rate we observed for 
HR-HPV infections was essentially the same as that seen in a population of Dutch women of comparable age, ${ }^{27}$ although the latter study observed a higher rate (14.3/ 1000 women-months, $95 \%$ CI 12.8 to 15.9 ) of LR-HPVs than we did in the present study (6.9 per 1000 women-months).

Approximately $58 \%$ of enrolled women were infected with HPV at some time during the follow-up. This is in agreement with previous studies, where 36-month cumulative rates ranged from $43 \%$ to $60 \%$ among university students. ${ }^{16} 1828$ Cumulative rates of HPV16, HPV18 or other types of $\alpha-7 / 9$ species were also comparable with the rates reported in other studies. ${ }^{15} 1618$ Further, 30\% of LR-HPVs and $49 \%$ of HR-HPVs samples were accompanied by other HPV types at the same visit.

Defining clearance of incident infections in the current study using the more conservative stringent definition more likely reflects the truly resolved infections and not false-negative results due to poor sampling, low levels of viral DNA or other measurement errors. ${ }^{18}$ 29-31 Therefore, duration of infections was clearly longer when using this definition. Similarly, other studies have also shown differences in duration using various definitions. ${ }^{32} 33$

Relative to other studies, we have seen similar rates of persistent infections in our cohort. On the basis of the liberal definition, the median duration until clearance of any HPV infection was 14.5 months, which is comparable to the median duration observed in a previous study (17.3 months). ${ }^{18}$

Differences in time intervals between samplings may explain the differences in perceived duration of an infection episode. The shorter intervals between cervicovaginal sampling (3 months) provide a more detailed assessment of the fluctuation in HPV detection over time relative to what can be observed with cervical sampling, which was performed at regular intervals of 6 months across the initial phase and the long-term follow-up period. Conceivably, interval fluctuation in HPV detection would not have affected clinical definitions of persistence, which are typically ascertained at 6 or 12 months postinitial testing. ${ }^{34} 35$

Apart from the high proportion of multiple infections observed in our cohort, the two different sampling methods and the 13-month gap between extended and long-term follow-up phases might have accounted for the long durations observed for infection clearance. Differences in findings between the two definitions were not unexpected; the conservative definition, by design, provided fewer events, thus requiring a lengthier observation period than the liberal definition. Despite these differences, our clearance results are in agreement with many previous studies reporting a median duration of LR-HPV infections between 6 and 10 months. ${ }^{2} 18293637$ Typically, average durations have been calculated in previous studies based on combining prevalent and incident cases. ${ }^{15-23}$ These differences in study design could affect the estimates of infection duration. We also acknowledge the complexity surrounding the definition of an incident HPV infection episode. ${ }^{38}$ Our definition was based on the extent that we could ascertain at the outset of the study that participants were not exposed to HPV of specific types.

In our cohort, $62 \%$ of women younger than 21 years were reported to have multiple sexual partners. Further, women with multiple partners had a greater risk (nearly twice) of acquiring new HR-HPV infections compared to women with one or no sexual partners. However, the rates were not strikingly different, as on an average, women had 2.3 partners, reflecting the fact that only women with $<6$ partners were eligible for enrolment. Also as expected, despite the restricted age range in this cohort, there was a clear difference in cumulative HPV detection based on age (higher in those <21 compared to $\geq 21$ years), reflecting a high HPV exposure following the onset of sexual activity.

In summary, we have observed high rates of HPV incidence, which varied according to HPV risk grouping, as well as to the type of the sample, sampling interval, age group and number of reported sexual partners. The primary strengths of our study were different sampling methods, younger population from multiple centres and comprehensive information on risk factors. Our findings on type-specific infection according to age and other risk factors provide insights into the natural history of HPV infection and improve our understanding of the dynamics of how infections with single and multiple HPV types are identified on repeated sampling over time. Although an apparent limitation, the age restriction imposed by the design of the trial allowed us to measure the variability in duration among HPV types at a time in a woman's life when her cervix is vulnerable to the oncogenic effects of HPV infection. These observations are important in designing strategies for infection monitoring during postvaccination surveillance. Our findings may also assist in designing cervical cancer screening algorithms based on molecular testing for HR-HPVs.

\section{Author affiliations}

${ }^{1}$ Division of Cancer Epidemiology, McGill University, Montreal, Quebec, Canada

${ }^{2}$ Federal University of Rio Grande do Sul-UFRGS/HCPA—Hospital de Clínicas de Porto Alegre, Porto Alegre, Brazil

${ }^{3}$ Leonor M de Barros Hospital, São Paulo, Brazil

${ }^{4}$ Department of Gynecology and Obstetrics, Gynecology and Obstetrics Infectious Diseases Sector, University of Parana, Curitiba, Parana, Brazil

${ }^{5}$ Instituto de Prevenção do Câncer, Fortaleza, Brazil

${ }^{6}$ Department of Gynecology, Oncology Division, State University of Campinas, Campinas, Brazil

${ }^{7}$ Pediatric Alliance, Pittsburgh, Pennsylvania, USA

${ }^{8}$ Department of Pediatrics, University of California, San Francisco, California, USA

${ }^{9}$ Geisel School of Medicine at Dartmouth, Hanover, New Hampshire, USA

${ }^{10}$ University of Alberta, Edmonton, Alberta, Canada

${ }^{11}$ Departments of Microbiology/Molecular Genetics, Dermatology \& Internal

Medicine, The University of Texas Medical School, Houston, Texas, USA

${ }^{12}$ First Line Medical Services Ltd., St. John's, Newfoundland and Labrador, Canada

${ }^{13}$ GSK Vaccines, King of Prussia, Pennsylvania, USA 
Current affiliation of DMH is University of Louisville School of Medicine, Louisville, KY 40202, USA.

Acknowledgements The first author (AVR) drafted the manuscript with the support of the senior author (ELF), a professional medical writer (Ramandeep Singh, employed by GSK group of companies, India) and the publication managers Matthieu Depuydt (Business \& Decision Life Sciences, Belgium) and Jérôme Leemans (Keyrus Biopharma, Belgium), both working on behalf of GSK Vaccines. The authors thank the study participants and their families; the study investigators and their staff members and the central and local teams of GSK Vaccines for their participation in the clinical studies HPV-001 (NCT00689741) and HPV-007 (NCT00120848).

Contributors MB, DMH, A-BM and SKT (US centres); PCdB, NSdC, PN, CMR-M and JCT (Brazilian centres) and ELF, BRa and BRo (Canadian centres) were principal investigators of clinical studies HPV-001 (NCT00689741) and HPV-007 (NCT00120848) and participated in the recruitment and/or follow-up of participants. At GlaxoSmithKline LLC (USA), GD and AS contributed towards study conception/design and supervised the conduct of these studies. AVR (McGill University) developed the statistical methodology used in the analysis of these epidemiological data, with the supervisory support of ELF (McGill University). All other authors reviewed and commented on initial and subsequent versions. All authors had full access to the data and gave final approval before submission.

Funding This work was supported by GlaxoSmithKline Biologicals S.A. The authors received no financial support or other form of compensation for the development of the manuscript. GlaxoSmithKline Biologicals S.A. assumed all costs associated with the development and publication of the present manuscript.

Competing interests MB, DMH, A-BM, PN, CMR-M, BRo, JCT and SKT have received, either directly or through their institution, research grants from the GSK group of companies to conduct the clinical studies reported here. MB has also received research grants and personal fees for conducting other clinical trials sponsored by Sanofi, Novartis and the GSK group of companies. $\mathrm{PN}$ and BRo have received research grants for other clinical trials sponsored by the GSK group of companies. Through her institution, DMH has received research grants for other HPV vaccine trials sponsored by Merck and the GSK group of companies. NSdC has received financial support from the GSK group of companies as clinical investigator for the PATRICIA trial and for lectures. BRo has received travel support and payment for expert testimony and speaking activities from the GSK group of companies. DMH has received payment from Merck and the GSK group of companies for her participation to advisory boards and speaker's bureaus. JCT has received payments from the GSK group of companies for lectures including service on speaker bureau and for participating in advisory board meetings. AVR has received reimbursement for travel expenses incurred during the presentation of these results at the International Papillomavirus Conference in 2011 (Berlin) and for presentation of results from additional epidemiological investigations at the International Papillomavirus Conference in 2012 (Puerto Rico). ELF has served as an occasional consultant to companies involved in HPV vaccines (Merck and GSK group of companies) and in HPV diagnostics (Roche, Gen-Probe, BD). His institution has received an unrestricted research grant from Merck. GD and AS are employees of the GSK group of companies. GD reports stock options and restricted shares from the GSK group of companies. GD holds patents in the Human Papillomavirus and in the Herpes Simplex virus vaccine fields. As reports stock options from the GSK group of companies. PCB and BRa declare no conflicts of interest.

\section{Patient consent Obtained.}

Ethics approval Independent Ethics Committees or Institutional Review Boards of the respective study centres (refer to Supplementary table 1 for a complete list).

Provenance and peer review Not commissioned; externally peer reviewed.

Data sharing statement No additional data are available.

Open Access This is an Open Access article distributed in accordance with the Creative Commons Attribution Non Commercial (CC BY-NC 4.0) license, which permits others to distribute, remix, adapt, build upon this work non- commercially, and license their derivative works on different terms, provided the original work is properly cited and the use is non-commercial. See: http:// creativecommons.org/licenses/by-nc/4.0/

\section{REFERENCES}

1. Walboomers JM, Jacobs MV, Manos MM, et al. Human papillomavirus is a necessary cause of invasive cervical cancer worldwide. J Pathol 1999;189:12-19.

2. Bosch FX, Burchell AN, Schiffman M, et al. Epidemiology and natural history of human papillomavirus infections and type-specific implications in cervical neoplasia. Vaccine 2008;26(Suppl 10): K1-16.

3. Moscicki $A B$, Widdice $L, M a Y$, et al. Comparison of natural histories of human papillomavirus detected by clinician- and self-sampling. Int J Cancer 2010;127:1882-92.

4. Sundstrom K, Eloranta S, Sparen P, et al. Prospective study of human papillomavirus (HPV) types, HPV persistence, and risk of squamous cell carcinoma of the cervix. Cancer Epidemiol Biomarkers Prev 2010;19:2469-78.

5. Castle PE, Rodriguez AC, Burk RD, et al. Long-term persistence of prevalently detected human papillomavirus infections in the absence of detectable cervical precancer and cancer. J Infect Dis 2011;203:814-22.

6. Schlecht NF, Kulaga S, Robitaille J, et al. Persistent human papillomavirus infection as a predictor of cervical intraepithelial neoplasia. JAMA 2001;286:3106-14

7. Richardson $\mathrm{H}$, Abrahamowicz M, Tellier PP, et al. Modifiable risk factors associated with clearance of type-specific cervical human papillomavirus infections in a cohort of university students. Cancer Epidemiol Biomarkers Prev 2005;14:1149-56.

8. Liaw KL, Glass AG, Manos MM, et al. Detection of human papillomavirus DNA in cytologically normal women and subsequent cervical squamous intraepithelial lesions. J Natl Cancer Inst 1999;91:954-60.

9. Kjaer SK, van den Brule AJ, Paull G, et al. Type specific persistence of high risk human papillomavirus (HPV) as indicator of high grade cervical squamous intraepithelial lesions in young women: population based prospective follow up study. BMJ 2002;325:572.

10. Kjaer SK, Frederiksen K, Munk C, et al. Long-term absolute risk of cervical intraepithelial neoplasia grade 3 or worse following human papillomavirus infection: role of persistence. J Natl Cancer Inst 2010;102:1478-88.

11. Bosch FX, Manos MM, Munoz N, et al. Prevalence of human papillomavirus in cervical cancer: a worldwide perspective. International biological study on cervical cancer (IBSCC) Study Group. J Natl Cancer Inst 1995;87:796-802.

12. Munoz N, Bosch FX, de Sanjose S, et al. Epidemiologic classification of human papillomavirus types associated with cervical cancer. N Engl J Med 2003;348:518-27.

13. Parada R, Morales R, Giuliano AR, et al. Prevalence, concordance and determinants of human papillomavirus infection among heterosexual partners in a rural region in central Mexico. BMC Infect Dis 2010;10:223.

14. Richardson H, Franco E, Pintos J, et al. Determinants of low-risk and high-risk cervical human papillomavirus infections in Montreal University students. Sex Transm Dis 2000;27:79-86.

15. Trottier H, Mahmud S, Prado JC, et al. Type-specific duration of human papillomavirus infection: implications for human papillomavirus screening and vaccination. $J$ Infect Dis 2008;197:1436-47.

16. Ho GY, Bierman R, Beardsley L, et al. Natural history of cervicovaginal papillomavirus infection in young women. $N$ Engl J Med 1998;338:423-8.

17. Kotloff KL, Wasserman SS, Russ K, et al. Detection of genital human papillomavirus and associated cytological abnormalities among college women. Sex Transm Dis 1998;25:243-50.

18. Richardson $\mathrm{H}$, Kelsall $\mathrm{G}$, Tellier $\mathrm{P}$, et al. The natural history of type-specific human papillomavirus infections in female university students. Cancer Epidemiol Biomarkers Prev 2003;12:485-90.

19. Brown DR, Shew ML, Qadadri B, et al. A longitudinal study of genita human papillomavirus infection in a cohort of closely followed adolescent women. J Infect Dis 2005;191:182-92.

20. Koshiol JE, Schroeder JC, Jamieson DJ, et al. Time to clearance of human papillomavirus infection by type and human immunodeficiency virus serostatus. Int J Cancer 2006;119:1623-9.

21. Molano $M$, Van den Brule A, Plummer $M$, et al. Determinants of clearance of human papillomavirus infections in Colombian women with normal cytology: a population-based, 5-year follow-up study. Am J Epidemiol 2003;158:486-94. 
22. Syrjanen S, Shabalova I, Petrovichev N, et al. Age-specific incidence and clearance of high-risk human papillomavirus infections in women in the former Soviet Union. Int J STD AIDS 2005;16:217-23.

23. Insinga RP, Dasbach EJ, Elbasha $\mathrm{EH}$, et al. Incidence and duration of cervical human papillomavirus $6,11,16$, and 18 infections in young women: an evaluation from multiple analytic perspectives. Cancer Epidemiol Biomarkers Prev 2007;16:709-15.

24. Harper DM, Franco EL, Wheeler C, et al. Efficacy of a bivalent L1 virus-like particle vaccine in prevention of infection with human papillomavirus types 16 and 18 in young women: a randomised controlled trial. Lancet 2004;364:1757-65.

25. Harper DM, Franco EL, Wheeler CM, et al. Sustained efficacy up to 4.5 years of a bivalent $L 1$ virus-like particle vaccine against human papillomavirus types 16 and 18: follow-up from a randomised control trial. Lancet 2006;367:1247-55.

26. Trottier H, Mahmud SM, Lindsay L, et al. Persistence of an incident human papillomavirus infection and timing of cervical lesions in previously unexposed young women. Cancer Epidemiol Biomarkers Prev 2009;18:854-62.

27. Schmeink CE, Massuger LF, Lenselink $\mathrm{CH}$, et al. Prospective follow-up of 2,065 young unscreened women to study human papillomavirus incidence and clearance. Int $\mathrm{J}$ Cancer 2013;133:172-81.

28. Winer RL, Hughes JP, Feng Q, et al. Comparison of incident cervical and vulvar/vaginal human papillomavirus infections in newly sexually active young women. $J$ Infect Dis 2009;199:815-18.

29. Franco EL, Villa LL, Sobrinho JP, et al. Epidemiology of acquisition and clearance of cervical human papillomavirus infection in women from a high-risk area for cervical cancer. $J$ Infect Dis $1999 ; 180: 1415-23$
30. Mori S, Nakao S, Kukimoto I, et al. Biased amplification of human papillomavirus DNA in specimens containing multiple human papillomavirus types by PCR with consensus primers. Cancer Sci 2011;102:1223-7.

31. Kleter B, van Doorn LJ, Schrauwen L, et al. Development and clinical evaluation of a highly sensitive PCR-reverse hybridization line probe assay for detection and identification of anogenital human papillomavirus. J Clin Microbiol 1999;37:2508-17.

32. Woodman CB, Collins S, Winter $\mathrm{H}$, et al. Natural history of cervical human papillomavirus infection in young women: a longitudinal cohort study. Lancet 2001;357:1831-6.

33. Moscicki AB, Shiboski S, Broering J, et al. The natural history of human papillomavirus infection as measured by repeated DNA testing in adolescent and young women. $J$ Pediatr 1998;132: 277-84.

34. Bosch FX, Lorincz A, Munoz N, et al. The causal relation between human papillomavirus and cervical cancer. J Clin Pathol 2002;55:244-65.

35. Fakhry C, Sugar E, D'Souza G, et al. Two-week versus six-month sampling interval in a short-term natural history study of oral HPV infection in an HIV-positive cohort. PLoS One 2010;5:e11918.

36. Moscicki AB, Palefsky J, Smith G, et al. Variability of human papillomavirus DNA testing in a longitudinal cohort of young women. Obstet Gynecol 1993;82:578-85.

37. Hildesheim A, Schiffman MH, Gravitt PE, et al. Persistence of type-specific human papillomavirus infection among cytologically normal women. J Infect Dis 1994;169:235-40.

38. Smelov V, Eklund C, Arroyo Mühr LS, et al. Are human papillomavirus DNA prevalences providing high-flying estimates of infection? An international survey of HPV detection on environmental surfaces. Sex Transm Infect 2013;89:627. 
Correction: Incidence and duration of type-specific human papillomavirus infection in high-risk HPV-naïve women: results from the control arm of a phase II HPV-16/18 vaccine trial

Ramanakumar AV, Naud P, Roteli-Martins CM, et al. Incidence and duration of typespecific human papillomavirus infection in high-risk HPV-naïve women: results from the control arm of a phase II HPV-16/18 vaccine trial. BMJ Open 2016;6:e11371. The paper has been resupplied online.

Open Access This is an Open Access article distributed in accordance with the Creative Commons Attribution Non Commercial (CC BY-NC 4.0) license, which permits others to distribute, remix, adapt, build upon this work noncommercially, and license their derivative works on different terms, provided the original work is properly cited and the use is non-commercial. See: http://creativecommons.org/licenses/by-nc/4.0/

BMJ Open 2016;4:e011371corr1. doi:10.1136/bmjopen-2016-011371corr1 